\title{
Integrative genomics analysis of hub genes and their relationship with prognosis and signaling pathways in esophageal squamous cell carcinoma
}

\author{
FANG-FANG CHEN $^{1 *}$, SHI-RONG ZHANG ${ }^{2 *}$, HAO PENG $^{1 *}$, YUN-ZHAO CHEN $^{3}$ and XIAO-BIN CUI ${ }^{1}$ \\ ${ }^{1}$ Department of Pathology and Key Laboratory for Xinjiang Endemic and Ethnic Diseases, \\ The First Affiliated Hospital, Shihezi University School of Medicine, Shihezi, Xinjiang 832002; \\ ${ }^{2}$ Department of Science and Education, The First Affiliated Hospital of Nanyang Medical College, Nanyang, \\ Henan 473000; ${ }^{3}$ The People's Hospital of Suzhou National Hi-Tech District, Suzhou, Jiangsu 215010, P.R. China
}

Received January 4, 2019; Accepted July 15, 2019

DOI: $10.3892 / \mathrm{mmr} .2019 .10608$

\begin{abstract}
The main purpose of the present study was to recognize the integrative genomics analysis of hub genes and their relationship with prognosis and signaling pathways in esophageal squamous cell carcinoma (ESCC). The mRNA gene expression profile data of GSE38129 were downloaded from the Gene Expression Omnibus database, which included 30 ESCC and 30 normal tissue samples. The differentially expressed genes (DEGs) between ESCC and normal samples were identified using the GEO2R tool. Gene Ontology and Kyoto Encyclopedia of Genes and Genomes (KEGG) pathway analyses were performed to identify the functions and related pathways of the genes. The protein-protein interaction (PPI) network of these DEGs was constructed with the Search Tool for the Retrieval of Interacting Genes and visualized with a molecular complex detection plug-in via Cytoscape. The top five important modules were selected from the PPI network. A total of 928 DEGs, including ephrin-A1 (EFNA1), collagen type IV $\alpha 1$ (COL4A1), C-X-C chemokine receptor 2 (CXCR2), adrenoreceptor $\beta 2$ (ADRB2), P2RY14, BUB1B, cyclin A2 (CCNA2), checkpoint kinase 1 (CHEK1), TTK, pituitary tumor transforming gene 1 (PTTG1) and COL5A1,
\end{abstract}

Correspondence to: Professor Yun-Zhao Chen, The People's Hospital of Suzhou National Hi-Tech District, 95 Huashan Road, Suzhou, Jiangsu 215010, P.R. China

E-mail:cyz0515@sina.com

Professor Xiao-Bin Cui, Department of Pathology and Key Laboratory for Xinjiang Endemic and Ethnic Diseases, The First Affiliated Hospital, Shihezi University School of Medicine, 71 North 2nd Road, Shihezi, Xinjiang 832002, P.R. China

E-mail: cuixiaobin4363@foxmail.com

*Contributed equally

Key words: esophageal squamous cell carcinoma, bioinformatics, gene expression, prognosis including 498 upregulated genes, were mainly enriched in the 'cell cycle', 'DNA replication' and 'mitotic nuclear division', whereas 430 downregulated genes were enriched in 'oxidation-reduction process', 'xenobiotic metabolic process' and 'cell-cell adhesion'. The KEGG analysis revealed that 'ECM-receptor interaction', 'cell cycle' and 'p53 signaling pathway' were the most relevant pathways. According to the degree of connectivity and adjusted P-value, eight core genes were selected, among which those with the highest correlation were CHEK1, BUB1B, PTTG1, COL4A1 and CXCR2. Gene Expression Profiling Interactive Analysis in The Cancer Genome Atlas database for overall survival (OS) was applied among these genes and revealed that EFNA1 and COL4A1 were significantly associated with a short OS in 182 patients. Immunohistochemical results revealed that the expression of PTTG1 in esophageal carcinoma tissues was higher than that in normal tissues. Therefore, these genes may serve as crucial predictors for the prognosis of ESCC.

\section{Introduction}

Esophageal squamous cell carcinoma (ESCC) is one of the most life-threatening types of cancer worldwide and the major histological type of esophageal cancer in East Asian countries (1). Approximately 455,800 new cases of esophageal cancer and 400,200 cases of esophageal cancer-related mortality occurred in 2012 worldwide; men with esophageal cancer have a three- to four-fold higher mortality rate than women (1). ESCC is an invasive tumor with a poor prognosis and is generally diagnosed only following the onset of symptoms. Although ESCC treatment has improved, the 5-year overall survival (OS) rate of patients with ESCC remains low due to insufficient understanding of its molecular pathogenesis and infrequent early-stage examination (2). Therefore, novel insights into the diagnosis and prognosis of ESCC can be obtained by increasing the level of understanding of its pathogenesis.

Similar to other types of cancer, the development of ESCC involves the gradual accumulation of vital gene mutations involved in cell cycle control, cell growth, differentiation, 
apoptosis, migration and invasion, or other functions, including the inactivation of tumor suppressor genes and activation of oncogenes (3). Zhang et al (4) found that ROC1 is expressed at a high level in ESCC and is associated with poor prognosis. Targeting the overexpressed ROC1 induces G2 cell cycle arrest and apoptosis in esophageal cancer cells. Hers et al (5) found that increasing the transduction of the Akt signaling pathway serves an important role in several types of cancer, including breast cancer (6), prostate cancer (7) and gastric cancer $(5,8)$. P53 is one of the most commonly mutated genes in human cancer, the overexpression of epidermal growth factor receptor and P53 mutation induces tumor development, invasion and differentiation (9). Although certain genes or proteins are involved in the development of ESCC, the pathogenic mechanisms remain unclear. Therefore, determining the pathogenesis of esophageal cancer-related signaling pathways and predicting the prognosis of esophageal cancer are crucial.

The present study aimed to identify the hub genes (Table I) related to the occurrence and development of esophageal cancer through bioinformatics analysis, and then examine the signaling pathways involved in these hub genes and their relationship with the prognosis of esophageal cancer. The present study aims to further improve current understanding of the occurrence and development of esophageal cancer.

\section{Materials and methods}

Microarray data. The GSE38129 gene expression dataset was submitted by $\mathrm{Hu}$ et al (10) and can be obtained from the publicly accessible Gene Expression Omnibus (GEO) database. The dataset was downloaded and analyzed from the GEO at the National Center for Biotechnology Information website (https://www.ncbi.nlm.nih.gov/geo/). The study was based on the GPL571 platform (Affymetrix Human Genome U133A 2.0 Array, Affymetrix; Thermo Fisher Scientific, Inc.). The samples used for gene profile analysis were obtained from 30 patients with ESCC and paired adjacent normal tissues, the patients were from high-risk areas of China, and the most recent update was in April 2017.

Data processing of differentially expressed genes (DEGs). GEO2R online software was used for GSE38129 analysis to detect the DEGs between the tumor and normal tissues. GEO2R is an interactive networking tool that helps users to compare various groups of samples in the GEO series and identify DEGs under specific experimental conditions. The adjusted $\mathrm{P}<0.01$ and $\mid \log$ fold change $(\mathrm{FC}) \mid>1$ values were used as the cut-off criteria for DEG identification. Subsequently, 928 DEGs were identified following GSE38129 analysis. Among these DEGs, 498 and 430 were upregulated and downregulated, respectively.

Gene Ontology (GO) function and Kyoto Encyclopedia of Genes and Genomes (KEGG) pathway enrichment analyses. GO analysis (https://david.ncifcrf.gov/) (11), which is a bioinformatics tool that can be used to annotate genes and gene products and determine the biological characteristics of high-throughput genome or transcriptome data, includes three categories, namely, biological process (BP), cellular component (CC) and molecular function (MF). The KEGG knowledge
Table I. Eight hub genes with a high degree of connectivity.

\begin{tabular}{lcc}
\hline Gene & Degree of connectivity & adj.P.Val \\
\hline CHEK1 & 88 & $1.64 \mathrm{E}-08$ \\
BUB1B & 84 & $2.10 \mathrm{E}-08$ \\
PTTG1 & 64 & $1.62 \mathrm{E}-04$ \\
COL4A1 & 16 & $2.26 \mathrm{E}-04$ \\
CXCR2 & 15 & $1.15 \mathrm{E}-08$ \\
ADRB2 & 12 & $2.15 \mathrm{E}-05$ \\
ACOX2 & 5 & $5.82 \mathrm{E}-06$ \\
EFNA1 & 4 & $1.27 \mathrm{E}-06$ \\
\hline
\end{tabular}

adj.P.Val, adjusted P-value.

database (12) is a group of databases used for all types of biological data and can be used to determine functional and metabolic pathways. $\mathrm{P}<0.05$ was set as the cut-off criterion and considered to indicate a statistically significant difference (Fig. S1). The Database for Annotation, Visualization and Integrated Discovery (DAVID) (13) is a web-based online bioinformatics resource and a functional interpretation tool with a large scale gene or protein dataset that can provide comprehensive functional annotation for genes.

Protein-protein interaction (PPI) network construction and module analysis. The Search Tool for the Retrieval of Interacting Genes (STRING; https://string-db.org/) (14) database is an online tool that contains comprehensive information of various proteins and detects potential associations among the DEGs. The results were input into Cytoscape to visualize the PPI networks of the DEGs. A high combined score indicated reliable PPIs. In the present study, interactions with a combined confidence of $>0.7$ were considered significant. The PPI network was constructed using Cytoscape software. The Molecular Complex Detection plug-in of Cytoscape (15) further indicated the essential modules in the PPI networks (degree node score cut-off=0.2, K-Core=2, degree cut-off=2).

Survival analysis. Gene Expression Profiling Interactive Analysis (GEPIA) (16) is a web-based server for cancer and normal gene expression analyses and interactive analysis on the basis of The Cancer Genome Atlas (TCGA) and Genotype-Tissue Expression (GTEx) data. Multiple types of analyses can be performed, including differential expression analysis, profiling plotting, correlation analysis and patient survival analysis. Through GEPIA analysis, ephrin-A1 (EFNA1) and collagen type IV $\alpha 1$ (COL4A1) were expressed at high levels in ESCC and were associated with a poor prognosis. The low expression of $\mathrm{C}-\mathrm{X}-\mathrm{C}$ chemokine receptor 2 (CXCR2) was not statistically significant.

Patients and samples. A total of 36 ESCC tissue samples and 35 normal esophageal tissue samples were collected for the present study, which had been surgically removed from Kazakh patients at the First Affiliated Hospital of Shihezi University (Xinjiang, China) between June 2018 to March 2019. The research protocol was approved by the Medical Ethics and 


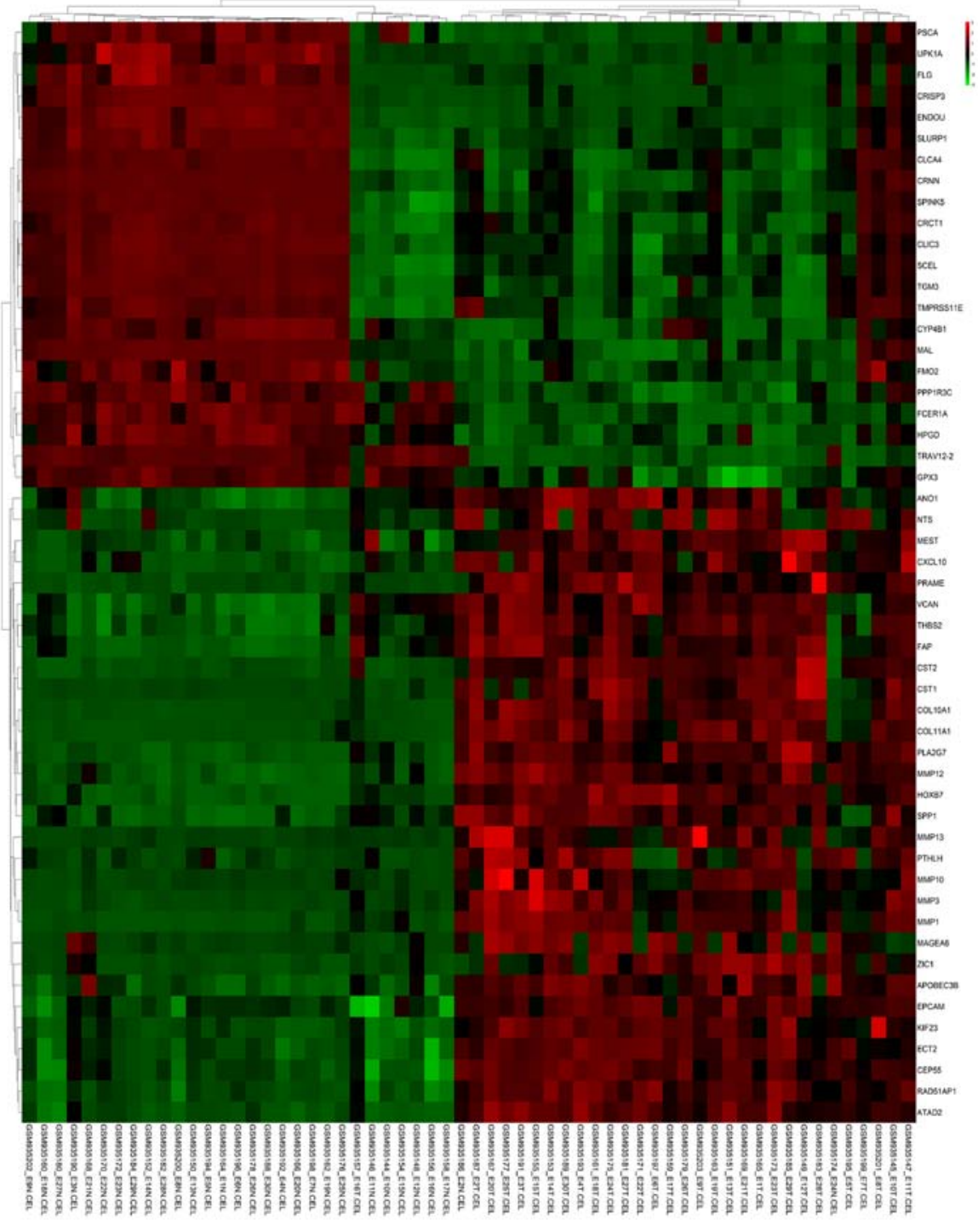

Figure 1. Heatmap of DEGs in ESCC and normal esophageal samples. The heatmap shows the DEGs between the ESCC and normal samples. When llogFCl was set to $>2.5$ and the P-value was adjusted to $<0.01,52$ differential genes, including 30 upregulated and 22 downregulated genes, were identified. The clustering of the samples is shown above the dendrogram and the level of gene expression signal us indicated by the color (red and green for high and low expression levels, respectively). ESCC, esophageal squamous cell carcinoma; DEGs, differentially expressed genes.

Human Clinical Trial Committee of Shihezi University School of Medicine (Xinjiang, China) and all recruited subjects were enrolled following the provision of written informed consent. All surgical samples were used as residual specimens following diagnostic sampling.

Immunohistochemistry (IHC). A total of 36 esophageal cancer tissue samples and 35 normal samples from Kazakh patients were selected from formalin-fixed and paraffin-embedded tissue chips. The sample tissue chips, with a diameter of $0.6 \mathrm{~mm}$, were obtained using ALPHELYS. The tissue microarrays were heated in an oven at $65^{\circ} \mathrm{C}$ for $30 \mathrm{~min}$, rehydrated with graded alcohols, immersed in ethylenediaminetetraacetic acid buffer $\left(\mathrm{pH} \mathrm{9.0)}\right.$ at $130^{\circ} \mathrm{C}$, and autoclaved in a microwave oven for $10 \mathrm{~min}$. Following cooling to $30^{\circ} \mathrm{C}$, the tissues were incubated at room temperature with $3 \% \mathrm{H}_{2} \mathrm{O}_{2}$ solution for $10 \mathrm{~min}$. The tissue sections were then incubated at $4^{\circ} \mathrm{C}$ with anti-securin antibody [also termed anti-pituitary tumor transforming gene 1 (PTTG1) antibody, Bioss antibodies, rabbit polyclonal, cat. no. bs-1881R, dilution 1:400] overnight. The tissue sections were organized and washed in PBS three times for $5 \mathrm{~min}$ each and then incubated with secondary antibody [universal kit (mouse/rabbit polymer method detection system), cat. no. PV6000, ZSGB, Ready-to-use antibody] at $37^{\circ} \mathrm{C}$ for $30 \mathrm{~min}$. Diaminobenzidine (DAB) solution was used for $5 \mathrm{~min}$ at room temperature and hematoxylin was used to counterstain the sections. The IHC score was performed independently by two pathologists using a light microscope (BX51; Olympus, Tokyo, Japan; magnification, x400) according to the color intensity as either negative (score 0 ), weak (score 1), moderate (score 2) or strong (score 3), and coloring area as negative (score 0 ), $\leq 10-25 \%$ (score 2), $25-50 \%$ (score 3 ) or $>50 \%$ (score 4 ). The final score was determined as the coloring intensity multiplied by the coloring area. Scores 0-4 and 5-12 indicated low and high expression groups, respectively.

Statistical analysis. Data were assessed using the SPSS (version 17.0; SPSS, Inc.) statistical software package, and 
Table II. Top 50 DEGs, including 19 upregulated and 31 downregulated genes.

\begin{tabular}{|c|c|c|c|c|}
\hline ID & adj.P.Val & P-value & $\log \mathrm{FC}$ & Gene \\
\hline \multicolumn{5}{|c|}{ Downregulated } \\
\hline 207802_at & $2.95 \mathrm{E}-08$ & $5.42 \mathrm{E}-10$ & -5.38992228 & CRISP3 \\
\hline 220090_at & $6.96 \mathrm{E}-06$ & $4.36 \mathrm{E}-07$ & -4.46587146 & CRNN \\
\hline 204777_s_at & $1.29 \mathrm{E}-07$ & 3.34E-09 & -4.3672882 & MAL \\
\hline 220620_at & 8.69E-06 & $5.70 \mathrm{E}-07$ & -3.9442306 & CRCT1 \\
\hline 206004_at & $4.68 \mathrm{E}-06$ & $2.68 \mathrm{E}-07$ & -3.94095422 & TGM3 \\
\hline 209613_s_at & $1.56 \mathrm{E}-08$ & $2.40 \mathrm{E}-10$ & -3.67537874 & ADH1B \\
\hline 220026_at & $1.61 \mathrm{E}-04$ & $1.80 \mathrm{E}-05$ & -3.65426494 & CLCA4 \\
\hline 214536_at & $1.05 \mathrm{E}-06$ & 4.61E-08 & -3.56033721 & SLURP1 \\
\hline 206884_s_at & $6.42 \mathrm{E}-05$ & $6.13 \mathrm{E}-06$ & -3.51463756 & SCEL \\
\hline 219529_at & $3.15 \mathrm{E}-06$ & $1.67 \mathrm{E}-07$ & -3.47635301 & CLIC3 \\
\hline 203914_x_at & $1.03 \mathrm{E}-09$ & $7.43 \mathrm{E}-12$ & -3.44800172 & HPGD \\
\hline 206605_at & $1.49 \mathrm{E}-08$ & $2.28 \mathrm{E}-10$ & -3.43754016 & ENDOU \\
\hline 215704_at & 7.39E-07 & $2.90 \mathrm{E}-08$ & -3.37242552 & FLG \\
\hline 213240_s_at & $3.44 \mathrm{E}-04$ & $4.35 \mathrm{E}-05$ & -3.31829107 & KRT4 \\
\hline 205185_at & $1.44 \mathrm{E}-04$ & $1.59 \mathrm{E}-05$ & -3.20158834 & SPINK5 \\
\hline 204284_at & $2.66 \mathrm{E}-10$ & $1.34 \mathrm{E}-12$ & -3.14636945 & PPP1R3C \\
\hline 210096_at & $1.07 \mathrm{E}-07$ & 2.68E-09 & -3.13376609 & CYP4B1 \\
\hline 220431_at & $1.03 \mathrm{E}-04$ & $1.08 \mathrm{E}-05$ & -3.13073801 & TMPRSS11E \\
\hline 207008_at & $1.15 \mathrm{E}-08$ & $1.61 \mathrm{E}-10$ & -3.11373209 & CXCR2 \\
\hline 205783_at & $4.37 \mathrm{E}-05$ & 3.91E-06 & -3.08906259 & KLK13 \\
\hline 206199_at & $9.59 \mathrm{E}-06$ & 6.39E-07 & -3.06841828 & CEACAM7 \\
\hline 201348_at & $1.59 \mathrm{E}-11$ & $2.07 \mathrm{E}-14$ & -3.06249067 & GPX3 \\
\hline 205767_at & $5.58 \mathrm{E}-08$ & $1.22 \mathrm{E}-09$ & -2.96580978 & EREG \\
\hline 212681_at & $1.24 \mathrm{E}-11$ & $1.40 \mathrm{E}-14$ & -2.9062456 & EPB41L3 \\
\hline 201325_s_at & 9.91E-08 & $2.46 \mathrm{E}-09$ & -2.78110281 & EMP1 \\
\hline 209365_s_at & $4.24 \mathrm{E}-07$ & $1.47 \mathrm{E}-08$ & -2.72959968 & ECM1 \\
\hline 211726_s_at & $7.83 \mathrm{E}-06$ & $5.04 \mathrm{E}-07$ & -2.71946544 & FMO2 \\
\hline 205319_at & $1.03 \mathrm{E}-06$ & 4.47E-08 & -2.67917377 & PSCA \\
\hline 211026_s_at & $4.92 \mathrm{E}-12$ & $2.43 \mathrm{E}-15$ & -2.61375129 & MGLL \\
\hline 207980_s_at & $1.36 \mathrm{E}-10$ & $5.35 \mathrm{E}-13$ & -2.57860425 & CITED2 \\
\hline 204614_at & $1.34 \mathrm{E}-03$ & 2.18E-04 & -2.55597414 & SERPINB2 \\
\hline \multicolumn{5}{|l|}{ Upregulated } \\
\hline 204620_s_at & $4.60 \mathrm{E}-08$ & $9.68 \mathrm{E}-10$ & 2.57111875 & VCAN \\
\hline 212353_at & $8.15 \mathrm{E}-08$ & $1.92 \mathrm{E}-09$ & 2.57383841 & SULF1 \\
\hline 204779_s_at & $2.10 \mathrm{E}-12$ & $7.56 \mathrm{E}-16$ & 2.57925018 & HOXB7 \\
\hline 214612_x_at & $1.06 \mathrm{E}-03$ & $1.66 \mathrm{E}-04$ & 2.61538749 & MAGEA6 \\
\hline 209942_x_at & $8.45 \mathrm{E}-04$ & $1.27 \mathrm{E}-04$ & 2.63065096 & MAGEA6///MAGEA3 \\
\hline 202859_x_at & $1.18 \mathrm{E}-06$ & 5.33E-08 & 2.6515207 & CXCL8 \\
\hline 205680_at & $3.82 \mathrm{E}-06$ & $2.11 \mathrm{E}-07$ & 2.72388472 & MMP10 \\
\hline 206632_s_at & $1.86 \mathrm{E}-08$ & $3.05 \mathrm{E}-10$ & 2.77430412 & АРОВЕС3В \\
\hline 204475_at & $1.12 \mathrm{E}-09$ & $8.31 \mathrm{E}-12$ & 4.8371858 & MMP1 \\
\hline 202404_s_at & $1.57 \mathrm{E}-07$ & 4.29E-09 & 2.84748214 & COL1A2 \\
\hline 202310_s_at & $3.58 \mathrm{E}-08$ & $6.90 \mathrm{E}-10$ & 3.00373934 & COL1A1 \\
\hline 206224_at & $1.58 \mathrm{E}-08$ & $2.43 \mathrm{E}-10$ & 3.04664986 & CST1 \\
\hline 206291_at & $6.57 \mathrm{E}-04$ & $9.38 \mathrm{E}-05$ & 3.19271902 & NTS \\
\hline 210809_s_at & $4.97 \mathrm{E}-07$ & $1.78 \mathrm{E}-08$ & 3.22856265 & POSTN \\
\hline 205157_s_at & $3.12 \mathrm{E}-06$ & $1.65 \mathrm{E}-07$ & 3.32873111 & KRT17///JUP \\
\hline 217428_s_at & $1.24 \mathrm{E}-11$ & $1.47 \mathrm{E}-14$ & 3.34429678 & COL10A1 \\
\hline 204580_at & $2.92 \mathrm{E}-09$ & $2.93 \mathrm{E}-11$ & 3.47409534 & MMP12 \\
\hline 37892_at & $4.08 \mathrm{E}-11$ & $8.94 \mathrm{E}-14$ & 4.18462587 & COL11A1 \\
\hline 209875_s_at & $3.55 \mathrm{E}-10$ & $1.94 \mathrm{E}-12$ & 4.46479482 & SPP1 \\
\hline
\end{tabular}

FC, fold change; adj.P.Val, adjusted P-value. 


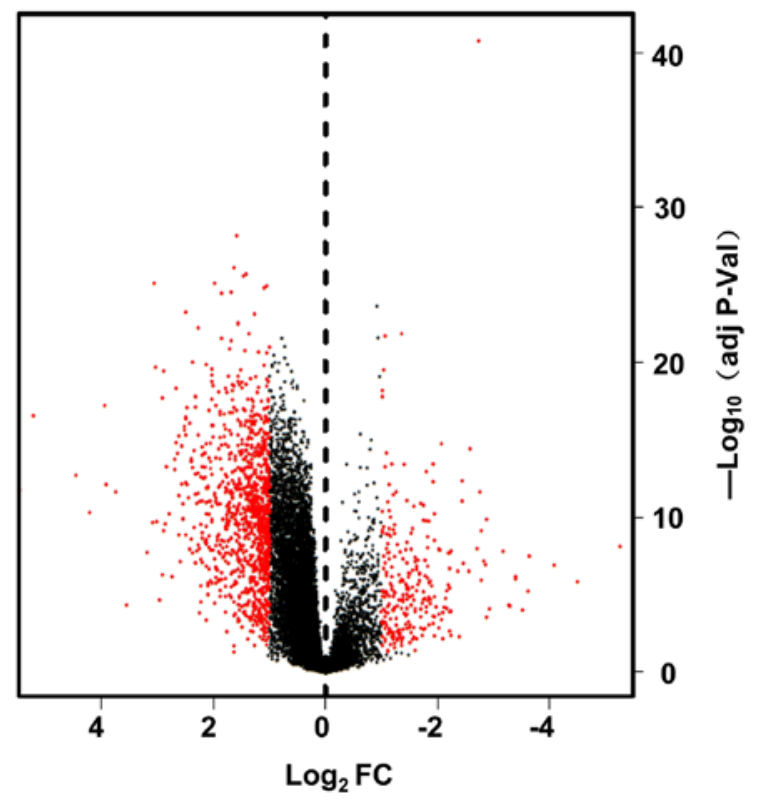

Figure 2. Volcano plot of all genes. A volcano plot of the differentially expressed genes between esophageal squamous cell carcinoma and normal samples is shown. The red dots on the left indicate upregulated genes, the red dots on the left and right and black dots indicate upregulated, downregulated and unregulated genes, respectively. FC, fold-change.

GraphPad Prism 5.0 (GraphPad Software, Inc.) was used to describe data. Comparisons of the expression levels of proteins between the $\operatorname{ESCC}(n=36)$ and normal tissues $(n=35)$ were performed using the independent-samples t-test and $\chi^{2}$ test. All data are presented as the mean \pm SD.

\section{Results}

DEG identification. The DEGs were detected using the GEO2R online analytical tool with adjusted $\mathrm{P}<0.01$ and $\mid \log \mathrm{FCl}>1$ as cut-off criteria. A total of 928 DEGs were obtained between the ESCC and normal samples, including 498 upregulated and 430 downregulated genes. Eight core genes were selected on the basis of the degree of connectivity and adjusted P-value (Table I), including checkpoint kinase 1 (CHEK1), BUB1B, PTTG1, COL4A1, CXCR2, adrenoreceptor $\beta 2$ (ADRB2), acyl-CoA oxidase 2 (ACOX2) and EFNA1. The top 50 DEGs are shown in Table II (19 upregulated and 31 downregulated genes). Additionally, by setting $\mid \log \mathrm{FCl}>2.5$ and adjusted $\mathrm{P}<0.01,52$ DEGs were selected, of which 30 and 22 were upregulated and downregulated, respectively. The heat maps and volcano plots show the different DEG samples (Figs. 1 and 2). These volcano plots and heat maps indicate all genes, and the top 52 DEGs, respectively.

GO and KEGG pathway analyses of DEGs. To appreciate the functions of the DEGs further, DAVID (https://david.ncifcrf. gov/) was used to apply the GO function and KEGG pathway for enrichment analysis. The BPs, CCs and MFs of the DEGs were annotated and classified by GO analysis. The present study identified $39 \mathrm{GO}$ terms on the basis of the DEGs of modules with a false discovery rate (FDR) $<0.05$ and count of $>2$ as thresholds and these terms were then sorted by the P-value. The top five enriched GO terms for the BPs, CCs and
MFs were selected from the GO terms (Fig. 3 and Table III). The signaling pathways were obtained through the KEGG database, and the major signaling pathways included 'cell cycle', 'ECM-receptor interaction', 'p53 signaling pathway', 'protein digestion and uptake', 'small cell lung cancer' and 'proteoglycans in cancer' (Table IV).

PPI network construction and module analysis. The STRING database was used to predict the interaction between 928 DEGs (minimum required interaction score of $>0.7$ ). To select important modules in the PPI network, the MCODE plug-in was used and 25 modules were found. The top five modules were also selected for further analysis, which included 60 , 15, 13, 32 and 7 genes (Table V). The DEGs in the top five modules were also enriched in important pathways (Fig. 4A-J). Module A had 60 nodes and 1,643 interactions, and all of the DEGs were upregulated in this module. The genes in this module, including CHEK1, cyclin A2 (CCNA2) and TTK, were considerably enriched in the cell cycle and p53 signaling pathway-related functions (Fig. 4B).

Survival analysis. Gene expression and survival analyses were performed by GEPIA in the TCGA database. The resulting box plots (Fig. 5A-H) showed that EFNA1 and COL4A1 were expressed at a high level in ESCC (Fig. 5B and C), whereas the expression of CXCR2 was low in ESCC (Fig. 5E). Survival analysis (Fig. 6A-H) further showed that EFNA1 and COL4A1 were associated with poor prognosis and exhibited statistically significant differences (Fig. 6B and C).

IHC features. According to the degree of connectivity and adjusted P-value, eight core genes were selected (Table I), among which the most strongly correlated genes were CHEK1 (degree of connectivity $=88$, adjusted $\mathrm{P}=1.64 \mathrm{E}-08$ ), BUB1B (degree of connectivity $=84$, adjusted $\mathrm{P}=2.10 \mathrm{E}-08$ ), PTTG1 (degree of connectivity $=64$, adjusted $\mathrm{P}=1.62 \mathrm{E}-04$ ), COL4A1 (degree of connectivity $=16$, adjusted $\mathrm{P}=2.26 \mathrm{E}-04$ ), and CXCR2 (degree of connectivity=15, adjusted $\mathrm{P}=1.15 \mathrm{E}-08$ ). No significant prognostic significance was found for CHEK1 or BUB1B (Fig. 6G and H). Relevant references were also reviewed and it was found that PTTG1 is an oncogene that is overexpressed in several tumors. The high expression of PTTG1 also exhibited a relatively poor prognosis through GEPIA survival analysis (Fig. 6A). Therefore, PTTG1 was selected for IHC analysis. IHC was used to detect the expression of PTTG1 in 36 ESCC tissue samples and 35 normal tissue samples of the Kazakh patients. The results showed that the expression of PTTG1 (Fig. 7A and B) in esophageal cancer tissues was significantly higher than that in normal tissues, and the difference was statistically significant $(\mathrm{P}=0.002)$. In addition, the PTTG1 IHC staining scores in the ESCC and normal tissues were compared using independent-samples t-test analysis, and the difference was statistically significant $(\mathrm{P}<0.001$; Fig. 7C).

\section{Discussion}

ESCC is a digestive tract tumor, is the fourth highest cause of cancer-associated mortality and is one of the most aggressive malignancies in China (17). In the present study, the online 
Table III. Top five BPs, CCs and MFs in the analysis of differentially expressed genes between ECSS and normal tissues.

\begin{tabular}{lcccc}
\hline Term & Count & P-value & FDR & Functional group \\
\hline GO:0051301 cell division & 59 & $4.21 \mathrm{E}-16$ & $8.10 \mathrm{E}-13$ & BP \\
GO:000008 G1/S transition of mitotic cell cycle & 30 & $7.47 \mathrm{E}-15$ & $1.36 \mathrm{E}-11$ & BP \\
GO:0030198 Extracellular matrix organization & 41 & $1.50 \mathrm{E}-14$ & $2.75 \mathrm{E}-11$ & BP \\
GO:0006260 DNA replication & 35 & $1.60 \mathrm{E}-13$ & $2.93 \mathrm{E}-10$ & $\mathrm{BP}$ \\
GO:0030574 collagen catabolic process & 22 & $1.79 \mathrm{E}-12$ & $3.28 \mathrm{E}-09$ & $\mathrm{BP}$ \\
GO:0070062 extracellular exosome & 229 & $1.55 \mathrm{E}-17$ & $2.27 \mathrm{E}-14$ & $\mathrm{CC}$ \\
GO:0005615 extracellular space & 127 & $1.20 \mathrm{E}-13$ & $1.76 \mathrm{E}-10$ & $\mathrm{CC}$ \\
GO:0031012 extracellular matrix & 47 & $1.32 \mathrm{E}-12$ & $1.93 \mathrm{E}-09$ & $\mathrm{CC}$ \\
GO:0005737 cytoplasm & 333 & $3.71 \mathrm{E}-10$ & $5.43 \mathrm{E}-07$ & $\mathrm{CC}$ \\
GO:0005654 nucleoplasm & 199 & $1.59 \mathrm{E}-09$ & $2.32 \mathrm{E}-06$ & $\mathrm{CC}$ \\
GO:0005515 protein binding & 515 & $2.55 \mathrm{E}-09$ & $4.07 \mathrm{E}-06$ & $\mathrm{MF}$ \\
GO:0005201 extracellular matrix structural constituent & 17 & $1.07 \mathrm{E}-07$ & $1.71 \mathrm{E}-04$ & $\mathrm{MF}$ \\
GO:0043142 single-stranded DNA-dependent & 7 & $2.46 \mathrm{E}-06$ & 0.003918 & $\mathrm{MF}$ \\
ATPase activity & & & & \\
GO:0005518 collagen binding & 14 & $5.39 \mathrm{E}-06$ & 0.008585 & $\mathrm{MF}$ \\
GO:0003678 DNA helicase activity & 9 & $1.20 \mathrm{E}-05$ & 0.019143 & $\mathrm{MF}$ \\
\hline
\end{tabular}

GO, Gene Ontology; BP, biological process; CC, cellular component; MF, molecular function; FDR, false discovery rate; Count, enriched gene number in the category.

Table IV. KEGG pathway analysis of differentially expressed genes.

\begin{tabular}{llccc}
\hline Category & \multicolumn{1}{c}{ Term } & Count & P-value & FDR \\
\hline hsa04110 & Cell cycle & 29 & $3.86 \mathrm{E}-10$ & $5.05 \mathrm{E}-07$ \\
hsa03030 & DNA replication & 16 & $4.92 \mathrm{E}-10$ & $6.43 \mathrm{E}-07$ \\
hsa04512: & ECM-receptor interaction & 23 & $3.24 \mathrm{E}-09$ & $4.24 \mathrm{E}-06$ \\
hsa05146 & Amoebiasis & 19 & $3.94 \mathrm{E}-05$ & 0.051506178 \\
hsa04974 & Protein digestion and absorption & 17 & $4.48 \mathrm{E}-05$ & 0.058547669 \\
hsa04510 & Focal adhesion & 28 & $6.69 \mathrm{E}-05$ & 0.087469624 \\
hsa04115 & p53 signaling pathway & 14 & $1.16 \mathrm{E}-04$ & 0.151932901 \\
hsa05222 & Small cell lung cancer & 14 & 0.001286708 & 1.670849429 \\
hsa03430 & Mismatch repair & 7 & 0.001721063 & 2.229032091 \\
hsa05200 & Pathways in cancer & 38 & 0.002816977 & 3.624393493 \\
hsa05202 & Transcriptional misregulation in cancer & 19 & 0.009704623 & 11.98140955 \\
hsa04114 & Oocyte meiosis & 14 & 0.011336843 & 13.861154 \\
hsa04151 & PI3K-Akt signaling pathway & 31 & 0.019748427 & 22.97410608 \\
hsa04972 & Pancreatic secretion & 12 & 0.020140081 & 23.37588312 \\
hsa05144 & Malaria & 8 & 0.023512051 & 26.75579741 \\
hsa05205 & Proteoglycans in cancer & 20 & 0.026031699 & 29.1909003 \\
hsa00590 & Arachidonic acid metabolism & 9 & 0.027995297 & 31.03652764 \\
hsa04914 & Progesterone-mediated oocyte maturation & 11 & 0.031059516 & 33.82807896 \\
hsa05219 & Bladder cancer & 7 & 0.03140939 & 34.14009186 \\
hsa00410 & beta-Alanine metabolism & 6 & 0.033090282 & 35.62023199 \\
hsa03320 & PPAR signaling pathway & 9 & 0.041960173 & 42.93477387 \\
hsa00071 & Fatty acid degradation & 7 & 0.042590557 & 43.42421223 \\
\hline
\end{tabular}

KEGG, Kyoto Encyclopedia of Gene and Genome; FDR, false discovery rate; Count, enriched gene number in the category. 
A

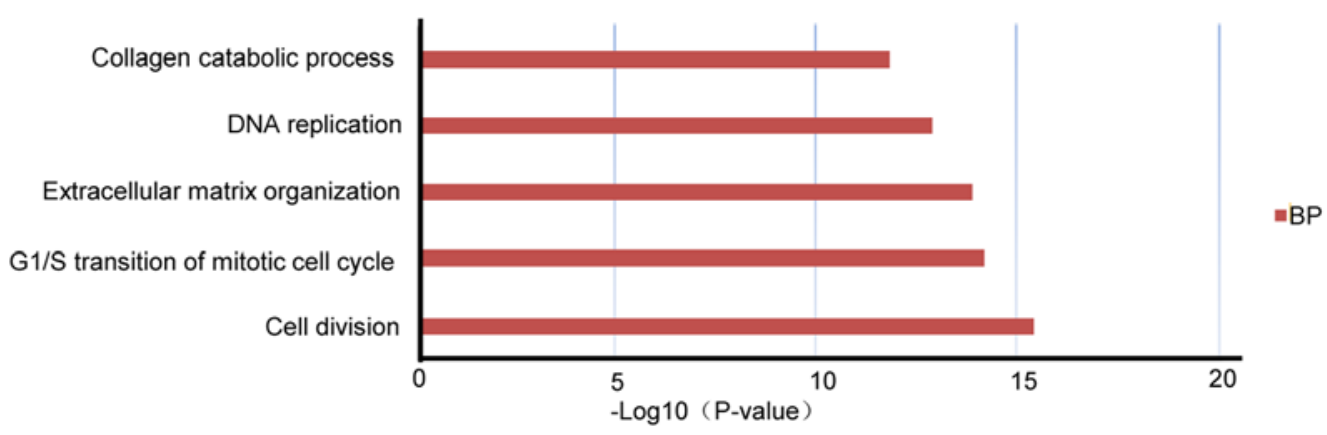

B

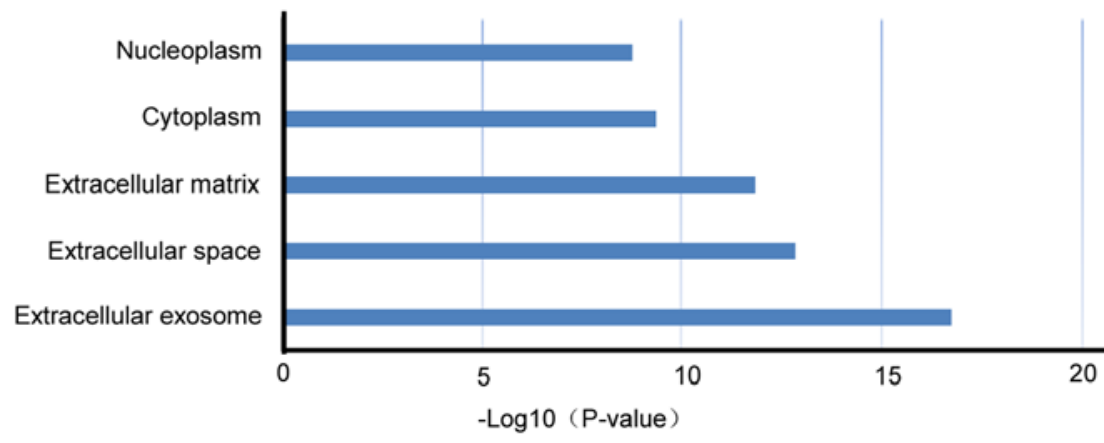

C

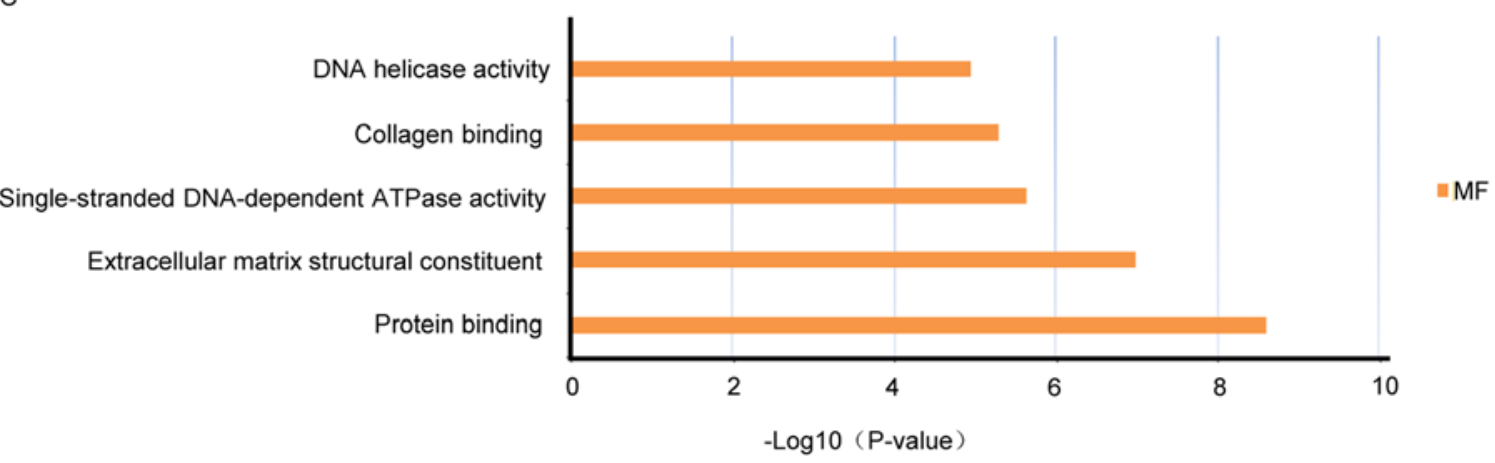

Figure 3. GO term enrichment analysis. (A) Top five clusters of DEGs in BPs (red). (B) Top five clusters of DEGs in CCs (blue). (C) Top five clusters of DEGs in MFs (orange). These groups are ranked and presented as bar plots according to their Fisher's exact P-value. DEGs, differentially expressed genes; GO, Gene Ontology; BP, biological process; CC, cellular component; MF, molecular function.

Table V. Modules of networks.

\begin{tabular}{lccc}
\hline Module name & Nodes & Edges & Cluster scores \\
\hline A & 60 & 1643 & 55.695 \\
B & 15 & 102 & 14.571 \\
C & 13 & 78 & 13.000 \\
D & 32 & 144 & 9.290 \\
E & 7 & 20 & 6.667 \\
\hline
\end{tabular}

GEO2R tool was used between ESCC and normal samples to detect 928 DEGs, including 498 upregulated and 430 downregulated genes. Using several bioinformatics tools, the DEGs were found to be mainly related to cell cycle, DNA replication and ECM-receptor interactions. A PPI network of the DEGs was also constructed, and the first five modules were selected for further analysis. All the genes enriched in module 1, including BUB1B, CCNA2, CHEK1, BUB1, CCNB1 and CCNB2, were upregulated. These genes were mainly related to cell cycle, progesterone-mediated oocyte, and the p53 signaling pathway.
The COL family of genes was mainly enriched in module 2, including COL11A1, COL1A1, COL1A2, COL5A1, COL5A2 and COL6A3, which was involved in the ECM-receptor interaction and PI3K-Akt signaling pathways. EFNA1 and COL4A1 were also associated with the prognosis of patients with ESCC.

EFNA1 is an angiogenic factor. EFNA1 was originally separated from human umbilical vein endothelial cells as a secretory protein and treated with tumor necrosis factor- $\alpha$. Tumor necrosis factor- $\alpha$-induced (18) EFNA1 and its receptor, Eph receptor 2, are associated with various types of cancer, including bladder cancer (19) and gastric cancer (20). High expression of EFNA1 is also involved in colorectal cancer (21) and its low expression is associated with a poor prognosis in clear cell renal cell carcinoma (22). High expression of COL4A1 is associated with advanced tumors and poor OS and disease-free survival in patients with HCC (23). COL4A1 knockdown decreases cell viability and cell cycle in breast cancer cells (24). Therefore, EFNA1 and COL4A1 may be associated with the prognosis of esophageal cancer. The GEPIA database in the TCGA was used in the present study for the survival analysis and it was found that EFNA1 and COL4A1 were associated with a poor prognosis in ESCC. 
A

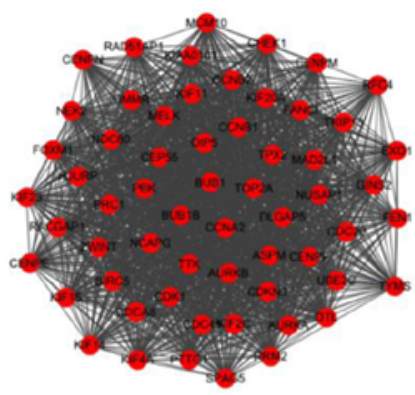

C

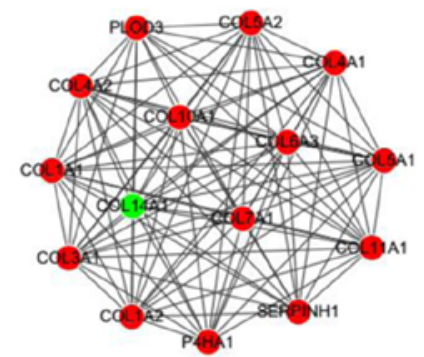

E

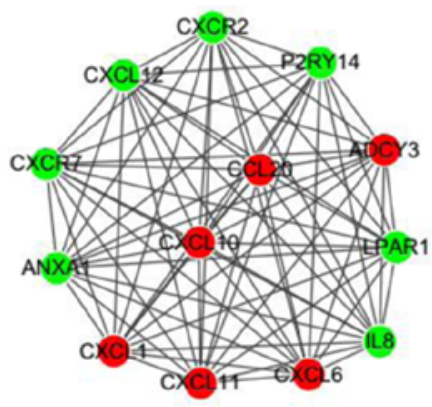

G

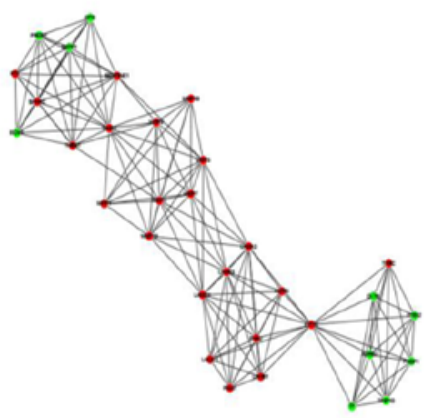

I

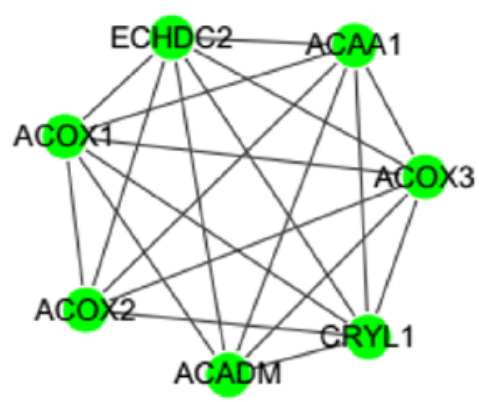

B

\begin{tabular}{|c|c|c|c|}
\hline Term & Count & FDR & Genes \\
\hline Cell cycle & 11 & $1.50 \mathrm{E}-11$ & $\begin{array}{l}\text { BUB1,BUB1BCCNA2CCNB1CCNB } \\
2 \text { 2CDC2OCDC45,CHEK1,MAD2L1,P } \\
\text { TTG1,TTK }\end{array}$ \\
\hline Oocyte meiosis & 7 & $3.40 \mathrm{E}-06$ & $\begin{array}{l}\text { AURKA BUB1,CCNB1,CCNB2,CDC2 } \\
0, \mathrm{MAD} 2 \mathrm{~L} 1, \mathrm{PT} T \mathrm{G} 1\end{array}$ \\
\hline $\begin{array}{l}\text { Progesterone-mediated } \\
\text { oocyte maturation }\end{array}$ & 5 & 0.000334 & 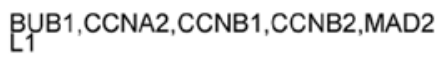 \\
\hline p53 signaling pathway & 4 & 0.00302 & CCNB1,CCNB2,CHEK1,RRM2 \\
\hline
\end{tabular}

D

\begin{tabular}{|c|c|c|c|}
\hline Term & Count & FDR & Genes \\
\hline $\begin{array}{l}\text { Protein digestion and } \\
\text { absorption }\end{array}$ & 11 & $1.09 \mathrm{E}-21$ & $\begin{array}{l}\text { COLL11A1,COL14A1,COL1A1,COL1A2,CO } \\
\text { L3A1,COL4A1, COLLAA2,COL5A1,COL5A2, } \\
\text { COL6A3,COL } 7 A 1\end{array}$ \\
\hline $\begin{array}{l}\text { ECM-receptor } \\
\text { interaction }\end{array}$ & 9 & $1.68 \mathrm{E}-16$ & $\begin{array}{l}\text { COL11A1,COL1A1,COL1A2,COL3A1,COL } \\
4 A 1, C O L 4 A 2, C O L 5 A 1, C O L 5 A 2, C O L 6 A 3\end{array}$ \\
\hline Focal adhesion & 9 & $2.55 \mathrm{E}-13$ & $\begin{array}{l}\text { COL11A1,COL1A1,COL1A2,COL3A1,COL } \\
4 A 1, C O L 4 A 2, C O L 5 A 1, C O L 5 A 2, C O L 6 A 3\end{array}$ \\
\hline $\begin{array}{l}\text { PI3K-Akt signaling } \\
\text { pathway }\end{array}$ & 9 & 2. & $\begin{array}{l}\text { COL11A1,COL1A1,COL1A2,COL3A1,COL } \\
4 A 1, C O L 4 A 2, C O L 5 A 1, C O L 5 A 2, C O L 6 A 3\end{array}$ \\
\hline
\end{tabular}

$\mathbf{F}$

\begin{tabular}{|c|c|c|c|}
\hline$\overline{T e r m}$ & Count & FDR & Genes \\
\hline$\overline{\text { Chemokine signaling pathway }}$ & 9 & $4.64 \mathrm{E}-14$ & $\begin{array}{l}\text { ADCY3,CCL20,CXCL1,CXCL10,CXC } \\
\text { L11,CXCL12,CXCL6,CXCR2,IL8 }\end{array}$ \\
\hline $\begin{array}{l}\text { Cytokine-cytokine receptor } \\
\text { interaction }\end{array}$ & 9 & $7.40 \mathrm{E}-13$ & $\begin{array}{l}\text { CCL20,CXCL1,CXCL10,CXCL11,CX } \\
\text { CL12,CXCL6,CXCR2,CXCR7,IL8 }\end{array}$ \\
\hline $\begin{array}{l}\text { Toll-like receptor signaling } \\
\text { pathway }\end{array}$ & 3 & 0.00178 & CXCL10,CXCL11,IL8 \\
\hline TNF signaling pathway & 3 & 0.00178 & CCL20,CXCL1,CXCL10 \\
\hline $\begin{array}{l}\text { NOD-like receptor signaling } \\
\text { pathway }\end{array}$ & 2 & 0.0202 & CXCL1,IL8 \\
\hline NF-kappa B signaling pathway & 2 & 0.0305 & CXCL12,IL8 \\
\hline
\end{tabular}

H

\begin{tabular}{|c|c|c|c|}
\hline$\overline{\text { Term }}$ & Count & FDR & Genes \\
\hline $\begin{array}{l}\text { EchM-receptor } \\
\text { interaction }\end{array}$ & 8 & $1.76 \mathrm{E}-10$ & $\begin{array}{l}\text { AGRN,FN1,AMA3,LAMB 1,LAMBB,LAMC1,L } \\
\text { AMC2,THBS1 }\end{array}$ \\
\hline Focal adhesion & 9 & 2.47E-09 & $\begin{array}{l}\text { EN1 LAMA3,'LAMB1,LAMB3,LAMC1,LAMC2, } \\
\text { PAK1,PAR2,THS1 }\end{array}$ \\
\hline Pathways in cancer & 9 & $9.80 \mathrm{E}-08$ & $\begin{array}{l}\text { FN1,LAMA3,LAMB1,LAMB3,LAMC1,LAMC2, } \\
\text { MMP1,MMP2,MMP9 }\end{array}$ \\
\hline Small cell lung cancer & 6 & 2.39E-07 & FN1,LAMA3,LAMB1,LAMB3,LAMC1,LAMC2 \\
\hline $\begin{array}{l}\text { Amoebiasis } \\
\text { Bladder cancer }\end{array}$ & $\begin{array}{l}6 \\
4\end{array}$ & $\begin{array}{l}6.97 \mathrm{E}-07 \\
1.50 \mathrm{E}-05\end{array}$ & $\begin{array}{l}\text { FN1,LAMA3,LAMB1,LAMB3,LAMC1,LAMC2 } \\
\text { MMP1,MMP2,MMP9,THBS1 }\end{array}$ \\
\hline $\begin{array}{l}\text { PI3K-Akt signaling } \\
\text { pathway }\end{array}$ & 7 & $2.89 \mathrm{E}-05$ & FN1,LAMA3,LAMB1,LAMB3,LAMC1,LAMC2, \\
\hline
\end{tabular}

\begin{tabular}{llll}
\hline Term & Count & FDR & Genes \\
\hline PPAR signaling pathway & 5 & $2.09 \mathrm{E}-09$ & ACAA1,ACADM,ACOX1,ACOX2,ACOX3 \\
Fatty acid degradation & 4 & $8.46 \mathrm{E}-08$ & ACAA1,ACADM,ACOX1,ACOX3 \\
Fatty acid metabolism & 4 & $8.88 \mathrm{E}-08$ & ACAA1,ACADM,ACOX1,ACOX3 \\
Peroxisome & 4 & $4.87 \mathrm{E}-07$ & ACAA1,ACOX1,ACOX2,ACOX3 \\
\hline
\end{tabular}

Figure 4. Top five modules from the protein-protein interaction network. (A) Module 1, (B) enriched pathways of module 1; (C) module 2, (D) enriched pathways of module 2; (E) module 3, (F) enriched pathways of module 3; (G) module 4, (H) enriched pathways of module 4; (I) module 5, (J) enriched pathways of module 5. Green and red nodes represent downregulated and upregulated genes, respectively.

The cell cycle is a process in which a cell completely divides, including interphase and division phases. The mechanism of cell cycle disorder in any condition causes the development of cancer, as cancer is closely associated with cell proliferation and growth (25). An important hallmark of cancer is uncontrolled cell proliferation. Tumor cells generally exhibit damage to genes that directly regulate cell cycle (26). In the present study, several DEGs were enriched in the cell cycle. COL1A1 
A



[num $(T)=182 ; \operatorname{num}(N)=286]$
B

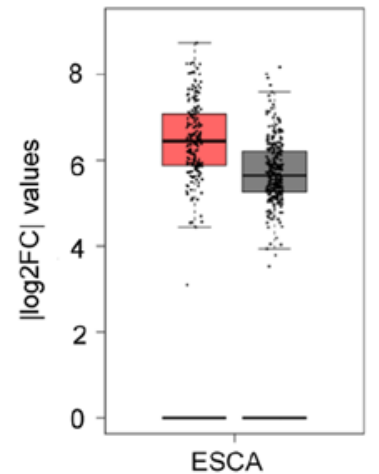

[num $(T)=182 ; \operatorname{num}(N)=286$ ]
C



[num $(T)=182$; $\operatorname{num}(\mathrm{N})=286$ ]
D



ESCA

[num $(\mathrm{T})=182 ; \operatorname{num}(\mathrm{N})=286$ ]

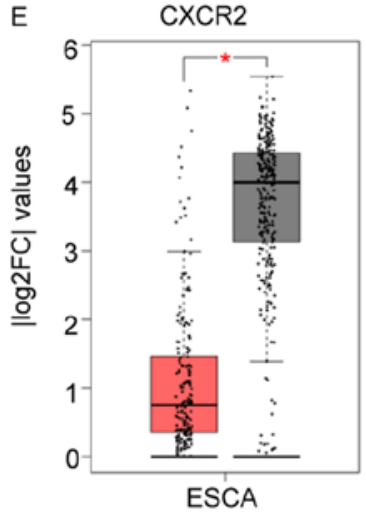

[num $(T)=182 ; \operatorname{num}(\mathrm{N})=286$ ]

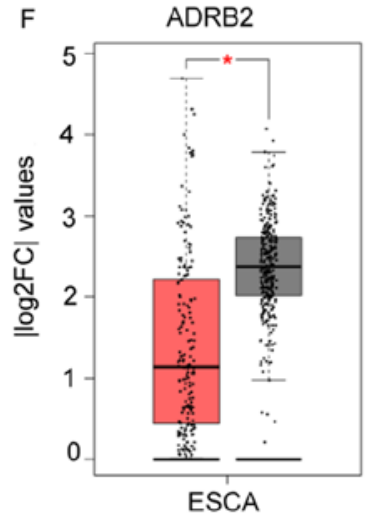

[num $(\mathrm{T})=182 ;$ num $(\mathrm{N})=286$ ]

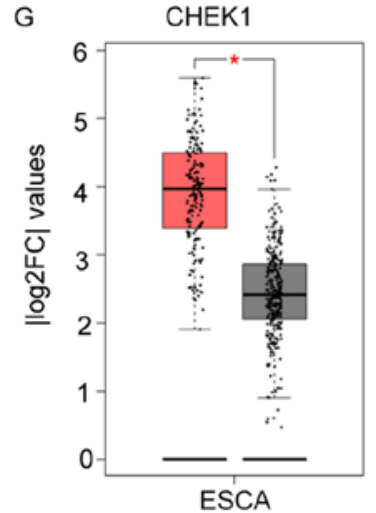

[num $(T)=182 ; \operatorname{num}(N)=286$ ]
$\mathrm{H}$

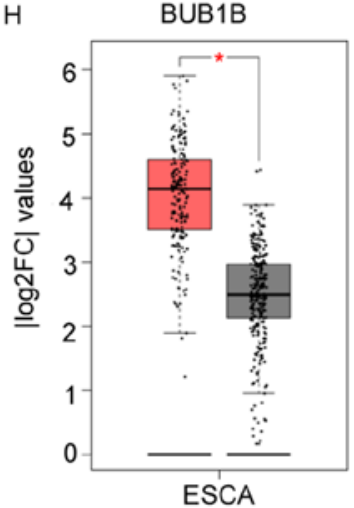

[num $(T)=182$; num $(N)=286$ ]

Figure 5. Box plots of ESCC and normal tissue expression levels in The Cancer Genome Atlas database. Box plots indicate the expression of different genes in tumor and normal tissues. The expression levels of (A) PTTG1 and (B) EFNA1 in ESCC tissues were higher than those in normal tissues, although there was no statistical significance. (C) COL4A1, (D) ACOX2, (E) CXCR2, (F) ADRB2, (G) CHEK1 and (H) BUB1B exhibited statistically significant differences. "P<0.05 between ESCC and normal tissues. ESCC tissues are shown in red, normal tissues are shown in black. Y-axis: $\mid \log 2 \mathrm{FCl}$ cut-off. X-axis: num (T)=182, num $(\mathrm{N})=286$. ESCC, esophageal squamous cell carcinoma; FC, fold-change; $\mathrm{T}$, tumor; $\mathrm{N}$, normal tissues.
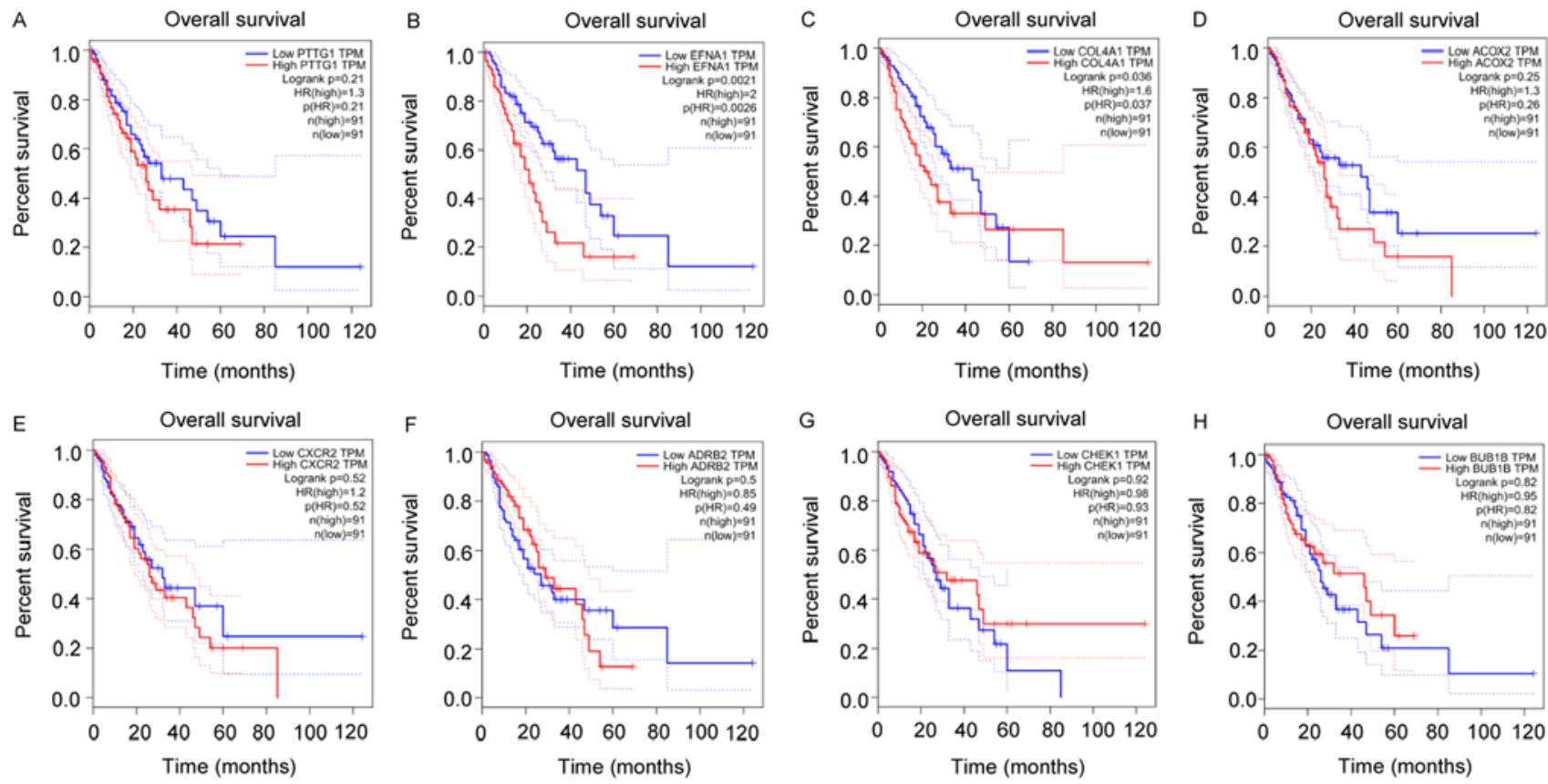

Figure 6. Prognostic value of eight hub genes in GSE38129. Relationships between gene expression and OS in 182 patient prognostic values in the GSE38129 of (A) PTTG1, (B) EFNA1, (C) COL4A1, (D) ACOX2, (E) CXCR2, (F) ADRB2, (G) CHEK1 and (H) BUB1B were obtained from Gene Expression Profiling Interactive Analysis. The results showed that the patients with high expression levels of EFNA1 $(\mathrm{P}=0.0026)$ and COL4A1 ( $\mathrm{P}=0.037)$ had a poorer prognosis than those with low expression levels of EFNA1 and COL4A1. ${ }^{*}<0.05$. OS, overall survival; HR, hazard ratio; TPM, number of transcripts per million reads. 

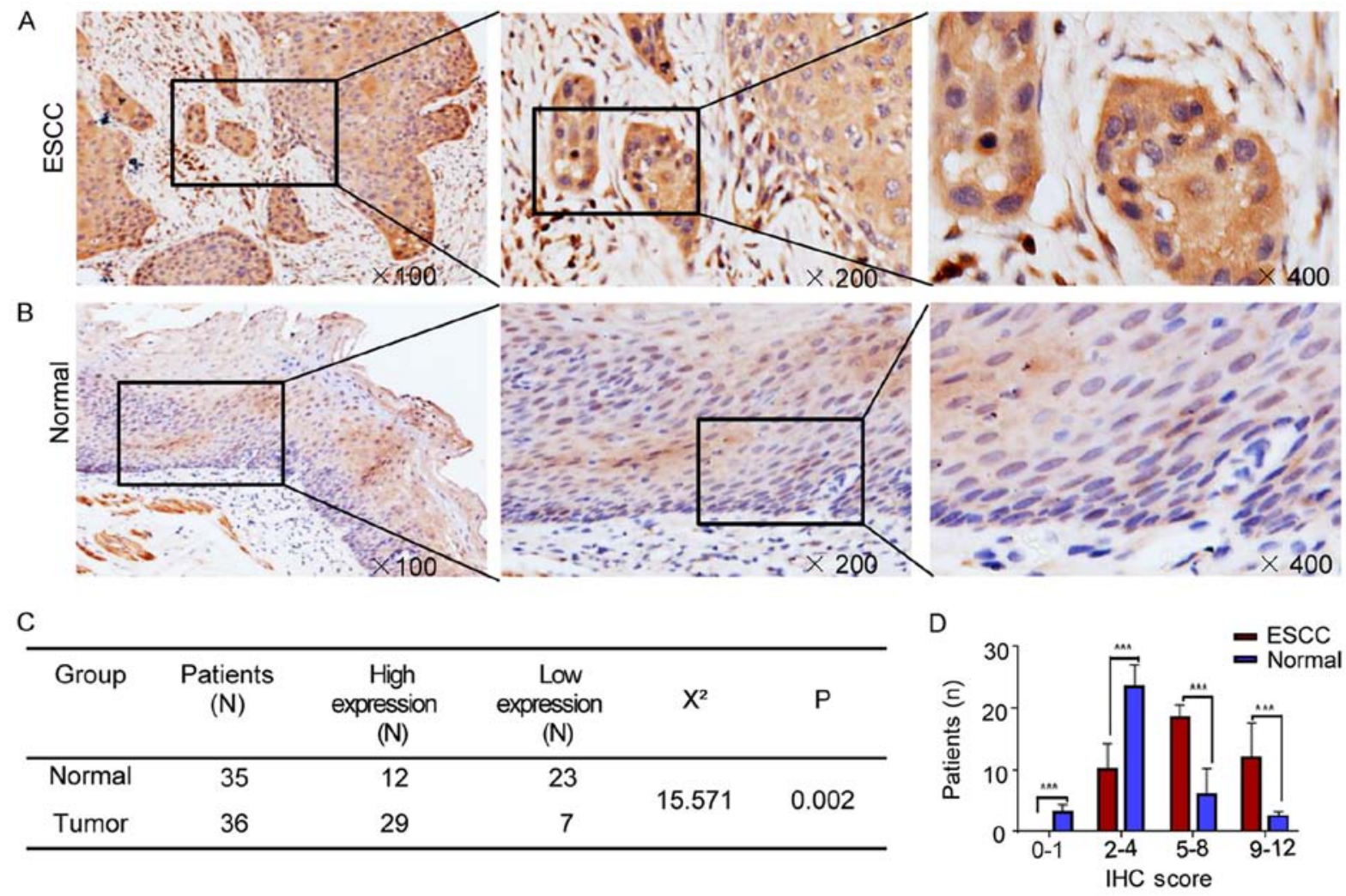

Figure 7. Protein expression of PTTG1 in ESCC and normal tissues. (A) Expression of PTTG1 in ESCC, cytoplasmic staining (magnification, $x 100$, $x 200$, $\mathrm{x} 400$ ). (B) Expression of PTTG1 in normal tissues, cytoplasmic staining (magnification, $\mathrm{x} 100, \mathrm{x} 200, \mathrm{x} 400$ ). (C) Expression of PTTG1 in ESCC tissues ( $\mathrm{n}=36$ ) was significantly higher than that in normal tissues $(\mathrm{n}=35)$, and the difference was statistically significant $(\mathrm{P}=0.002)$. (D) PTTG1 IHC staining score in ESCC and normal tissues using independent-samples t-test analysis; each bar represents the mean $\pm \mathrm{SD}$. ${ }^{* * *} \mathrm{P}<0.001$. ESCC, esophageal squamous cell carcinoma; IHC, immunohistochemistry.

and COL1A2 encode the $\alpha 1$ and $\alpha 2$ chains of type I collagen, respectively (27). The cell adhesion molecule COL1A1 is expressed at a high level in ESCC, which is essential for ESCC carcinogenesis (28). CHEK1 is also type of protein-coding gene. The protein encoded by CHEK1 belongs to the Ser/Thr protein kinase family. Checkpoints that mediate cell cycle arrest require the presence of DNA damage or unreplicated DNA. The high cytoplasmic expression of phosphorylated CHEK1 was associated with the poor prognosis of breast cancer (29) and also exhibited high expression in ovarian and oral squamous cell carcinoma $(30,31)$. Therefore, the targeted regulation of CHEK1 may become a novel method for cancer treatment.

PTTG1 is an oncogene that is overexpressed in several tumor types. The expression of PTTG1 is high in bladder cancer.PTTG1 knockdown significantly inhibits bladder cancer cell migration, invasion, metastasis and growth, and induces G0/G1 phase senescence and cell cycle arrest (32). Feng et al (33) reported that PTTG1, via activating the expression of GLI1 in ESCC, was involved in the epithelial-mesenchymal transformation (EMT) process, and promoted the metastasis in ESCC cell lines and tissues by inducing EMT. Particularly in cells with lymph node metastasis. TTK, also referred to as Mps1, is overexpressed in human pancreatic cancer and primary liver cancer $(34,35)$. BUB1B, which is a mitotic checkpoint serine/threonine kinase $\mathrm{B}$, is a member of the spindle assembly checkpoint protein family and is involved in various types of cancer. The expression of BUB1B is high in prostate cancer and associated with poor prognosis (36). BUB1B is also expressed at a high level in lung adenocarcinoma, and the overexpression of BUB1B is associated with poor disease progression and poor survival rates in patients with lung adenocarcinoma (37). Certain transcription factors can regulate ESCC cancer cell cycle by regulating BUB1B, which is a cell cycle-related DEG, thereby promoting the development of ESCC (38). Therefore, BUB1B may promote the development of ESCC by deregulating the cell cycle.

The present study identified DEGs through bioinformatics analysis, some of which may serve an important role in the development, progression and prognosis of ESCC. CHEK1 and BUB1B are primarily related to the cell cycle, and COL5A1, COL11A1 and COL1A1 are related to the main ECM-receptor interaction pathway. Through KEGG analysis, these differentially expressed genes were mainly related to cell cycle and ECM receptors. CHEK1, BUB1B, COL5A1, PTTG1, TTK and COL1A1 have also been associated with the development of various types of cancer. EFNA1 and COL4A1 were associated with the prognosis of ESCC. The IHC results showed that the expression of PTTG1 in ESCC tissues was significantly higher than that in normal esophageal tissues, with statistical significance. However, the present study used mostly consultation cases from the People's Hospital of Xinjiang Uyghur Autonomous Region, and the Xinjiang Yili Prefecture Friendship Hospital; ESCC fresh samples are difficult to obtain due to the lack of patients in this region, therefore, it is difficult to collect proteins for further analysis. In future research, when additional fresh tissue samples are collected, reverse transcription-PCR and western blot analyses will be performed for the validation of 
these identified target genes in clinical samples. In conclusion, the genes identified may serve an important role in the occurrence and prognosis of ESCC. However, their mechanism in ESCC requires further investigation.

\section{Acknowledgements}

Not applicable.

\section{Funding}

This study was supported by grants from the National Natural Science Foundation of China (grant nos. 81460362, 81773116, 81760436, 81560399 and 81360358), the Medical And Health Science And Technology Project Of Suzhou High Tech Zone (grant no. 2017Z006), the Applied Basic Research Projects of Xinjiang Production and Construction Corps (grant no. 2016AG020), the Major Science And Technology Projects of Shihezi University (grant no. gxjs2014-zdgg06), the High-Level Talent Project of Shihezi University (grant no. RCZX201533) and the Foundation for Distinguished Young Scholars of Shihezi University (grant no. 2015ZRKXJQ02). The funders were not involved in the study design, data collection and analysis, decision to publish, or preparation of the manuscript.

\section{Availability of data and materials}

The datasets analyzed in the present study are available from the GEO repository (https://www.ncbi.nlm.nih.gov/geo/query/acc. cgi?acc=GSE38129).

\section{Authors' contributions}

XBC and FFC conceived and designed the study. YZC, HP and SRZ collected the expression data and screened for the differentially expressed genes. FFC and HP analyzed and interpreted the data. FFC wrote the manuscript. XBC and YZC reviewed and edited the manuscript. All authors read and approved the final manuscript.

\section{Ethics approval and consent to participate}

The present study was approved by the Medical Ethics and Human Clinical Trial Committee of Shihezi University School of Medicine, and all recruited subjects were enrolled following the provision of written informed consent.

\section{Patient consent for publication}

Not applicable.

\section{Competing interests}

The authors declare that they have no competing interests.

\section{References}

1. Torre LA, Bray F, Siegel RL, Ferlay J, Lortet-Tieulent J and Jemal A: Global cancer statistics, 2012. CA Cancer J Clin 65: 87-108, 2015.
2. Cui XB, Zhang SM, Xu YX, Dang HW, Liu CX, Wang LH, Yang L, Hu JM, Liang WH, Jiang JF, et al: PFN2, a novel marker of unfavorable prognosis, is a potential therapeutic target involved in esophageal squamous cell carcinoma. J Transl Med 14: 137, 2016.

3. Ma S, Bao JY, Kwan PS, Chan YP, Tong CM, Fu L, Zhang N, Tong AH, Qin YR, Tsao SW, et al: Identification of PTK6, via RNA sequencing analysis, as a suppressor of esophageal squamous cell carcinoma. Gastroenterology 143: 675-686 e612, 2012.

4. Zhang J, Li S, Shang Z, Lin S, Gao P, Zhang Y, Hou S, Mo S, Cao W, Dong Z, et al: Targeting the overexpressed ROC1 induces G2 cell cycle arrest and apoptosis in esophageal cancer cells. Oncotarget 8: 29125-29137, 2017.

5. Hers I, Vincent EE and Tavare JM: Akt signalling in health and disease. Cell Signal 23: 1515-1527, 2011.

6. Durán-Prado M, Gahete MD, Hergueta-Redondo M, Martínez-Fuentes AJ, Cordóba-Chacón J, Palacios J, Gracia-Navarro F, Moreno-Bueno G, Malagón MM, Luque RM and Castaño JP: The new truncated somatostatin receptor variant sst5TMD4 is associated to poor prognosis in breast cancer and increases malignancy in MCF-7 cells. Oncogene 31: 2049-2061, 2012.

7. Wang J, Lu Y, Wang J, Koch AE, Zhang J and Taichman RS: CXCR6 induces prostate cancer progression by the AKT/mammalian target of rapamycin signaling pathway. Cancer Res 68: 10367-10376, 2008.

8. Matsuoka T and Yashiro M: The role of PI3K/Akt/mTOR signaling in gastric carcinoma. Cancers (Basel) 6: 1441-1463, 2014.

9. Okawa T, Michaylira CZ, Kalabis J, Stairs DB, Nakagawa H, Andl CD, Johnstone CN, Klein-Szanto AJ, El-Deiry WS, Cukierman E, et al: The functional interplay between EGFR overexpression, hTERT activation, and p53 mutation in esophageal epithelial cells with activation of stromal fibroblasts induces tumor development, invasion, and differentiation. Genes Dev 21: 2788-2803, 2007.

10. Hu N, Wang C, Clifford RJ, Yang HH, Su H, Wang L, Wang Y, $\mathrm{Xu}$ Y, Tang ZZ, Ding T, et al: Integrative genomics analysis of genes with biallelic loss and its relation to the expression of mRNA and micro-RNA in esophageal squamous cell carcinoma. BMC Genomics 16: 732, 2015.

11. Ashburner M, Ball CA, Blake JA, Botstein D, Butler H, Cherry JM, Davis AP, Dolinski K, Dwight SS, Eppig JT, et al: Gene ontology: Tool for the unification of biology. The Gene Ontology Consortium. Nat Genet 25: 25-29, 2000.

12. Altermann E and Klaenhammer TR: Pathwayvoyager: Pathway mapping using the kyoto encyclopedia of genes and genomes (KEGG) database. BMC Genomics 6: 60, 2005.

13. Huang DW, Sherman BT, Tan Q, Kir J, Liu D, Bryant D, Guo Y, Stephens R, Baseler MW, Lane HC and Lempicki RA: DAVID bioinformatics resources: Expanded annotation database and novel algorithms to better extract biology from large gene lists. Nucleic Acids Res 35: W169-W175, 2007.

14. Franceschini A, Szklarczyk D, Frankild S, Kuhn M, Simonovic M, Roth A, Lin J, Minguez P, Bork P, von Mering C and Jensen LJ: STRING v9.1: Protein-protein interaction networks, with increased coverage and integration. Nucleic Acids Res 41: D808-D815, 2013.

15. Bader GD and Hogue CW: An automated method for finding molecular complexes in large protein interaction networks. BMC Bioinformatics 4: 2, 2003

16. Tang Z, Li C, Kang B, Gao G, Li C and Zhang Z: GEPIA: A web server for cancer and normal gene expression profiling and interactive analyses. Nucleic Acids Res 45: W98-W102, 2017.

17. Cui XB, Pang XL, Li S, Jin J, Hu JM, Yang L, Liu CX, Li L, Wen SJ, Liang WH, et al: Elevated expression patterns and tight correlation of the PLCE1 and NF- $\mathrm{BB}$ signaling in Kazakh patients with esophageal carcinoma. Med Oncol 31: 791, 2014.

18. Holzman LB, Marks RM and Dixit VM: A novel immediate-early response gene of endothelium is induced by cytokines and encodes a secreted protein. Mol Cell Biol 10: 5830-5838, 1990.

19. Abraham S, Knapp DW, Cheng L, Snyder PW, Mittal SK, Bangari DS, Kinch M, Wu L, Dhariwal J and Mohammed SI: Expression of EphA2 and Ephrin A-1 in carcinoma of the urinary bladder. Clin Cancer Res 12: 353-360, 2006.

20. Nakamura R, Kataoka H, Sato N, Kanamori M, Ihara M, Igarashi H, Ravshanov S, Wang YJ, Li ZY, Shimamura T, et al: EPHA2/EFNA1 expression in human gastric cancer. Cancer Sci 96: 42-47, 2005. 
21. Yamamoto $H$, Tei M, Uemura $M$, Takemasa I, Uemura $Y$, Murata K, Fukunaga M, Ohue M, Ohnishi T, Ikeda K, et al: Ephrin-A1 mRNA is associated with poor prognosis of colorectal cancer. Int J Oncol 42: 549-555, 2013.

22. Wada H, Yamamoto H, Kim C, Uemura M, Akita H, Tomimaru Y, Hama N, Kawamoto K, Kobayashi S, Eguchi H, et al: Association between ephrin-A1 mRNA expression and poor prognosis after hepatectomy to treat hepatocellular carcinoma. Int J Oncol 45 1051-1058, 2014.

23. Désert R, Mebarki S, Desille M, Sicard M, Lavergne E, Renaud S, Bergeat D, Sulpice L, Perret C, Turlin B, et al: 'Fibrous nests' in human hepatocellular carcinoma express a Wnt-induced gene signature associated with poor clinical outcome. Int J Biochem Cell Biol 81: 195-207, 2016.

24. Salem O, Erdem N, Jung J, Münstermann E, Wörner A, Wilhelm H, Wiemann S and Körner C: The highly expressed 5 'isomiR of hsa-miR-140-3p contributes to the tumor-suppressive effects of miR-140 by reducing breast cancer proliferation and migration. BMC Genomics 17: 566, 2016.

25. Alabsi AM, Lim KL, Paterson IC, Ali-Saeed R and Muharram BA: Cell cycle arrest and apoptosis induction via modulation of mitochondrial integrity by Bcl-2 family members and caspase dependence in Dracaena cinnabari-treated H400 human oral squamous cell carcinoma. Biomed Res Int 2016: 4904016, 2016.

26. He Y, Liu J, Zhao Z and Zhao H: Bioinformatics analysis of gene expression profiles of esophageal squamous cell carcinoma. Dis Esophagus 30: 1-8, 2017.

27. Chan TF, Poon A, Basu A, Addleman NR, Chen J, Phong A, Byers PH, Klein TE and Kwok PY: Natural variation in four human collagen genes across an ethnically diverse population. Genomics 91: 307-314, 2008.

28. Yue Y, Song M, Qiao Y, Li P, Yuan Y, Lian J, Wang S and Zhang Y: Gene function analysis and underlying mechanism of esophagus cancer based on microarray gene expression profiling. Oncotarget 8: 105222-105237, 2017.

29. Abdel-Fatah TM, Middleton FK, Arora A, Agarwal D, Chen T, Moseley PM, Perry C, Doherty R, Chan S, Green AR, et al: Untangling the ATR-CHEK1 network for prognostication, prediction and therapeutic target validation in breast cancer. Mol Oncol 9: 569-585, 2015
30. Kim MK, James J and Annunziata CM: Topotecan synergizes with CHEK1 (CHK1) inhibitor to induce apoptosis in ovarian cancer cells. BMC Cancer 15: 196, 2015.

31. Parikh RA, Appleman LJ, Bauman JE, Sankunny M, Lewis DW, Vlad A and Gollin SM: Upregulation of the ATR-CHEK1 pathway in oral squamous cell carcinomas. Genes Chromosomes Cancer 53: 25-37, 2014.

32. Xiang W, Wu X, Huang C, Wang M, Zhao X, Luo G, Li Y, Jiang G, Xiao X and Zeng F: PTTG1 regulated by miR-146-3p promotes bladder cancer migration, invasion, metastasis and growth. Oncotarget 8: 664-678, 2017.

33. Feng W, Xiaoyan X, Shenglei L, Hongtao L and Guozhong J: PTTG1 cooperated with GLI1 leads to epithelial-mesenchymal transition in esophageal squamous cell cancer. Oncotarget 8: 92388-92400, 2017.

34. Kaistha BP, Honstein T, Müller V, Bielak S, Sauer M, Kreider R, Fassan M, Scarpa A, Schmees C, Volkmer H, et al: Key role of dual specificity kinase TTK in proliferation and survival of pancreatic cancer cells. Br J Cancer 111: 1780-1787, 2014.

35. Miao R, Wu Y, Zhang H, Zhou H, Sun X, Csizmadia E, He L, Zhao Y, Jiang C, Miksad RA, et al: Utility of the dual-specificity protein kinase TTK as a therapeutic target for intrahepatic spread of liver cancer. Sci Rep 6: 33121, 2016.

36. Fu X, Chen G, Cai ZD, Wang C, Liu ZZ, Lin ZY, Wu YD, Liang YX, Han ZD, Liu JC and Zhong WD: Overexpression of BUB1B contributes to progression of prostate cancer and predicts poor outcome in patients with prostate cancer. Onco Targets Ther 9: 2211-2220, 2016.

37. Chen H, Lee J, Kljavin NM, Haley B, Daemen A, Johnson L and Liang Y: Requirement for BUB1B/BUBR1 in tumor progression of lung adenocarcinoma. Genes Cancer 6: 106-118, 2015.

38. Zhang Y, Xu Y, Li Z, Zhu Y, Wen S, Wang M, Lv H, Zhang F and Tian Z: Identification of the key transcription factors in esophageal squamous cell carcinoma. J Thoracic Dis 10: 148-161, 2018. International (CC BY-NC-ND 4.0) License. 